\title{
DEMARCAÇÃO DE TERRAS INDÍGENAS E SISTEMA INTERAMERICANO DE DIREITOS HUMANOS: A RESPONSABILIDADE DO ESTADO POR ATO JUDICIAL
}

\section{DEMARCATION OF INDIGENOUS LAND AND THE INTER-AMERICAN SYSTEM OF HUMAN RIGHTS: STATE'S RESPONSABILITY FOR JUDICIAL ACT}

\section{RESUMO}

${ }^{1}$ Leila Bijos

${ }^{2}$ Cristina Nascimento de Melo

Este artigo analisa os direitos dos povos indígenas às terras que ocupam, tanto à luz do sistema jurídico interno brasileiro, como em relação ao Sistema Interamericano de Direitos Humanos. Discute a jurisprudência do Supremo Tribunal Federal sobre o caso Raposa Serra do Sol, de modo a verificar a possibilidade de responsabilização internacional do Brasil por ato do Poder Judiciário que restrinja a abrangência das normas protetivas dos direitos territoriais indígenas.

PALAVRAS-CHAVE: Demarcação de terras indígenas; Sistema Interamericano de Direitos Humanos; Responsabilidade Internacional do Estado

\begin{abstract}
This article analyzes the property rights of indigenous peoples to the lands they occupy both according to the Brazilian domestic legal system and the Inter-American Human Rights System. It discusses the Supreme Court jurisprudence in the case of Raposa Serra do Sol, aiming at verifying the possibility of Brazilian accountability by the judiciary act that restricted the internal protective rules of indigenous land rights.
\end{abstract}

KEYWORDS: Indigenous land demarcation; Inter-american System of Human Rights; State's international responsibility

\footnotetext{
1 Pós-Doutora pela Saint Mary's University, (Canadá). Doutora em Sociologia do Desenvolvimento pela Universidade de Brasília - UnB, Brasília, DF, (Brasil). Professora do Mestrado em Direito, Universidade Católica de Brasília -UCB, Brasília, DF, (Brasil). E-mail: leilabijos@gmail.com.

${ }^{2}$ Mestre em Direito, Universidade Católica de Brasília -UCB, Brasília, DF, (Brasil).Procuradora da República Ilhéus, BA, (Brasil). Financiamento: Ministério Público Federal - MPT. E-mail.:
} 


\section{INTRODUÇÃO}

O Brasil se apresenta como potência regional com importância estratégica junto aos países da América Latina. Essa estratégia se faz presente em termos de seu relevante potencial econômico e político. Do ponto de vista estatístico são 17 milhões de quilômetros quadrados, 400 milhões de habitantes, representando cerca de $70 \%$ de toda a América Latina e 6\% da população mundial, com integração lingüística, em que povos de língua portuguesa e espanhola, inglesa e francesa se comunicam e convivem de forma amigável. Destacam-se enormes riquezas em recursos minerais e energéticos, petróleo e gás, pesca agricultura e pecuária, no entanto, é necessário pensar nas assimetrias inerentes desta divisão política.

À América do Sul atribui-se a centralidade da democracia no hemisfério, o que permite a consolidação dos processos de integração, apesar do caráter diferenciado de cada país e subregião. A responsabilidade do Brasil como indutor do crescimento econômico e promotor da paz, da estabilidade e do desenvolvimento social na região é um marco da política externa brasileira desde a época do Império, prevalecendo durante a República, de forma imutável, num ambiente de intenso relacionamento com seus vizinhos, excetuando-se as ações militares no Prata e a guerra do Paraguai durante o século $\mathrm{XIX}^{3}$. Os vínculos com os países sulamericanos foram impulsionados e aprimorados continuamente, através de soluções de arbitragem, ou negociação de tratados bilaterais, no que tangia aos problemas territoriais e de fronteiras inerentes ao início do século XX.

Dentre os tratados mais relevantes ressaltam-se o Tratado da Bacia do Prata, firmado em 1969, e o Tratado de Cooperação Amazônica, concluído em 1978, ambos representando dois instrumentos importantes com objetivos específicos para a integração física, o desenvolvimento harmônico da nossa política sul-americana.

No entanto, verificam-se conflitos internos e externos, especialmente pela posse da terra, dos recursos minerais, e pelo gerenciamento da região Amazônica. Garimpeiros brasileiros invadem as terras indígenas em busca de minerais, como ouro, prata, chumbo, em acirradas disputas, que na maioria das vezes, culminam em assassinatos. Os países fronteiriços Colômbia, Suriname, Venezuela, são alvos de grileiros, garimpeiros ilegais,

\footnotetext{
${ }^{3}$ SANTOS, Eduardo dos. América do Sul, palestra apresentada na IV Conferência Nacional de Política Externa e Política Internacional, 3 e 4 de dezembro de 2009, organizada pela Fundação Alexandre de Gusmão e seu Instituto de Pesquisa de Relações Internacionais (texto acadêmico), p. 1.
}

Revista Brasileira de Direito Internacional le-SSN: 2526-0219| Curitiba | v. 2 | n. 2 | p. 23 - 38 | Jul/Dez. 2016. 
migrantes, o que gera constantes atritos entre as populações locais, cujas disputas são mediadas pelas autoridades nacionais.

Os povos indígenas passaram um longo período sob o manto da invisibilidade quanto a um dos seus direitos mais basilares - e referenciais da sua própria identidade - o direito a terra. Entretanto, atualmente consolidou-se uma destacável proteção a tal direito, tanto na ordem interna, quanto na ordem internacional, de modo que a multiculturalidade hoje figura como premissa na formulação e aplicação das leis, que detém, por sua vez, como núcleo axiológico, a dignidade da pessoa humana e o direito ao reconhecimento.

O Sistema das Nações Unidas de Direitos Humanos não apresenta um monitoramento particular dos direitos territoriais dos povos indígenas, de modo que o instrumento juridicamente vinculante, do qual o Brasil é signatário, é a Convenção no 169 da OIT.

Essa Convenção é aplicada pela Corte Interamericana de Direitos Humanos de forma integrativa com a Convenção Interamericana de Direitos Humanos, à luz do princípio in dubio pro homine, de modo a estabelecer um sistema o quanto mais amplo e eficaz possível de proteção aos direitos territoriais indígenas.

No âmbito local, as normas internacionais interagem com a Constituição Federal, independentemente da hierarquia supralegal ou da consolidação de um "bloco de constitucionalidade", também voltadas à aplicação da norma mais clara, específica e que melhor habilite o julgador a garantir o direito vindicado.

Diante de tais possibilidades, o presente artigo confronta a decisão do Supremo Tribunal Federal brasileiro tomada no Caso Raposa Serra do Sol (Pet no 3.388/RR) ao sistema de proteção dos direitos humanos, de modo a analisar se a imposição da necessidade de ocupação no momento da promulgação da Constituição como condição ao direito à posse das terras é compatível com os tratados de Direitos Humanos dos quais o Brasil é signatário.

Sendo incompatível, este trabalho abordará a possibilidade de responsabilização do Estado perante a Corte Interamericana de Direitos Humanos pelo referido ato judicial.

\section{DIREITOS TERRITORIAIS DOS POVOS INDÍGENAS NA ORDEM INTERNACIONAL}

A descoberta do "outro" traz implicações profundas nas formulações existenciais do "eu" e nos rumos da sociedade majoritariamente estabelecida. Isso porque, como explica 
Tzvetan TODOROV (2014, p. 3), é possível conceber o outro como um grupo social concreto ao qual nós não pertencemos. Este grupo pode ser contido numa sociedade: mulheres para homens, os ricos para os pobres, os loucos para os "normais". Ou pode ser exterior a ela, uma outra sociedade que, dependendo do caso, será próxima ou longínqua: seres que em tudo se aproximam de nós ou desconhecidos.

Há um grande desafio a ser enfrentado pelas sociedades modernas no sentido de não só incluir o diferente, como também oferecer o reconhecimento em um plano social de acordo com a cosmovisão de cada identidade. Numa realidade em que múltiplas cosmologias interagem através de canais linguísticos nem sempre democráticos e reclamam reconhecimento aos Estados constituídos, tem razão Amartya SEN (2007, p. 16) ao afirmar:

Nossa humanidade comum é barbaramente desafiada a partir do momento em que múltiplas divisões do Mundo são unificadas num só sistema de classificação supostamente dominante - em termos de religião, comunidade, cultura, nação ou civilização (tratando cada um como única força no contexto dessa abordagem específica da guerra e da paz). Um mundo assim dividido torna-se muito mais desagregado do que o universo das categorias plurais e diversas que efectivamente moldam o Mundo que vivemos.

Relevando-se tal enfrentamento à gramática dos direitos humanos, o direito à identidade (o direito a ser diferente) assume que esse "outro" é também sujeito de direitos ou, nas palavras de Flávia PIOVESAN, "um ser merecedor de igual consideração e profundo respeito, dotado do direito de desenvolver as potencialidade humanas, de forma livre, autônoma e plena" (2010, p. 48).

Identidade aqui é tomada segundo a concepção formuladas por Charles TAYLOR (1994, p. 54) que destaca "identidade: é aquilo que nós somos, de onde nós proviemos" e acrescenta:

A importância do reconhecimento é, agora, universalmente admitida, de uma forma ou de outra: no plano íntimo, estamos todos conscientes de como a identidade pode ser formada ou deformada no decurso da nossa relação com os outros-importantes; no plano social, temos uma política permanente de reconhecimento igualitário.

Nessa lógica, os povos indígenas são abarcados pela comunhão nacional como também detentores de direitos basilares e comuns a toda sociedade envolvente (à liberdade, à vida, à locomoção, dentro outros). 
Contudo, tal acepção igualitária não é imemorial, mas emerge da lei escrita, como nos lembra Fábio Konder COMPARATO “essa convicção de que todos os seres humanos têm direito a ser igualmente respeitados, pelo simples fato de sua humanidade, nasce vinculada a uma instituição social de capital importância: a lei escrita" (2010, p. 24).

Os índios possuem também direitos voltados às vulnerabilidades específicas dos grupos e à proteção da identidade das diversas comunidades. São direitos complexos, coletivos e interconectados. O que Daniela IKAWA denomina de "direitos especiais" (2010, p. 501).

Os direitos gerais e os direitos ditos "especiais" são esculpidos de acordo com seus propósitos nucleares. Eventuais restrições somente são justificáveis quando não vulnerarem a própria existência desses direitos, de modo que, na célebre frase de Boaventura de Sousa SANTOS, "as pessoas e os grupos sociais têm o direito a ser iguais quando a diferença inferioriza, e o direito de ser diferentes quando a igualdade os descaracteriza" (1997, p. 122).

Ainda nessa linha, Hélder Girão BARRETO (2004, p. 105) destaca "Interessante notar que somos acostumados a discorrer e defender o 'direito à igualdade', quando ao que parece mais adequado aos tempos pós-modernos seria propugnar pelo 'direito à diferença."

Como exemplo de primeira importância da categoria de "direitos especiais" figura o direito à propriedade e à posse de terras que ocupem, expresso no art. 14 da Convenção da Organização Internacional do Trabalho sobre Povos Indígenas e Tribais.

Ainda na escala global, a Declaração das Nações Unidas sobre os Direitos dos povos indígenas é bastante clara ao afirmar no art. 26:

1. Os povos indígenas têm direito às terras, territórios e recursos que possuem e ocupam tradicionalmente ou que tenham de outra forma utilizado ou adquirido.

2. Os povos indígenas têm o direito de possuir, utilizar, desenvolver e controlar as terras, territórios e recursos que possuem em razão da propriedade tradicional ou de outra forma tradicional de ocupação ou de utilização, assim como aqueles que de outra forma tenham adquirido.

3. Os Estados assegurarão reconhecimento e proteção jurídicos a essas terras, territórios e recursos. Tal reconhecimento respeitará adequadamente os costumes, as tradições e os regimes de posse da terra dos povos indígenas a que se refiram.

Apesar da Declaração constituir um instrumento de soft law, portanto, não vinculante ou obrigatório, espelha o desenvolvimento das normas internacionais sobre a temática 
indigenista e o comprometimento dos Estados a adotarem as diretrizes e princípios nela consolidados. Nesse sentido, Alexandre Gonçalves LIPPEL (2014, p. 56) destaca que:

\begin{abstract}
Por seu conteúdo, a Declaração estabelece um novo patamar internacional no tocante aos direitos dos povos indígenas. Constitui um ponto de chegada, pois consolida e sintetiza os avanços realizados no direito internacional dos direitos dos povos indígenas, aprofundando e ampliando direitos que estão na Convenção $\mathrm{n}^{\circ} 169$ da OIT, e incorpora demandas indígenas. Mas é também um ponto de partida, pois sua efetividade depende do comprometimento dos estado do sistema das Nações Unidas.
\end{abstract}

Já no sistema interamericano de direitos humanos, a proteção aos direitos territoriais indígenas decorre da interpretação evolutiva ${ }^{4}$ do art. 21 da Convenção Americana de Direitos Humanos - CADH (Pacto de San José da Costa Rica), que trata do direito à propriedade privada sem dispor sobre quaisquer nuances multiculturais.

Integram o sistema interamericano de monitoramento dos direitos dos povos indígenas a Comissão Interamericana de Direitos Humanos e a Relatoria Especial sobre Direitos Indígenas, criada em 1990. A comissão admite petições individuais e, por vezes, tem levado casos à Corte Interamericana, quando o Estado não cumpre as recomendações da Comissão e onde o Estado haja reconhecido a jurisdição da Corte.

A Corte Interamericana de Direitos Humanos, além de deter função consultiva, figura como órgão de jurisdição internacional, o que lhe outorga competência para analisar possíveis violações, por ato ou omissão dos Estados-parte das disposições instituídas na Convenção Americana de Direitos Humanos e em outros tratados que possam ser objeto de cognição deste mesmo órgão.

Utilizando-se de regras de interpretação não restritivas expostas no art. 29 da Convenção Americana de Direitos Humanos (CADH), a Corte Interamericana de Direitos Humanos abarcou dimensões como a propriedade coletiva, a territorialidade, a ancestralidade e a sacralidade, indispensáveis à compreensão da cosmovisão do índio com a terra, que ultrapassa, inclusive, o modelo civilista. Como destaca Mario MELO (2006, p. 34) "But the sense and scope stipulated through civil law on private property rights are not sufficient to

\footnotetext{
${ }^{4}$ Confira-se sobre interpretação evolutiva da Convenção Interamericana de Direitos Humanos: Caso dos Irmãos Gómez Paquiyauri. Sentença de 8 de julho de 2004. Série C No 110, párr. 165; Caso da Comunidade Mayagna (Sumo) Awas Tingni, nota 176 supra, par. 146; Caso das "Crianças de Rua” (Villagrán Morales e outros), nota 182 supra, par. 193, e o Direito à Informação sobre a Assistência Consular no Marco das Garantias do Devido Processo Legal. Parecer Consultivo OC-16/97 de 14 de novembro de 1997. Série A No 16, par. 114.
}

Revista Brasileira de Direito Internacional le-SSN: 2526-0219| Curitiba | v. 2 | n. 2 | p. 23 - 38 | Jul/Dez. 2016. 
contain the much wider aggregate of realities that must be seen by the international law on human rights."

Seguindo essas diretrizes, a Corte Interamericana, no julgamento do caso Awas Tingui vs. Nicarágua (2001, p.78), afirmou que é dever do Estado delimitar, demarcar e titular o território das comunidades indígenas, além de se abster de realizar atos que impeçam o uso e gozo dos bens localizados nessas áreas enquanto a delimitação não ocorrer:

Para las comunidades indígenas la relación con la tierra no es meramente una cuestión de posesión y producción sino un elemento material y espiritual del que deben gozar plenamente, inclusive para preservar su legado cultural y transmitirlo a las generaciones futura.

A integração entre as normas previstas na Convenção n ${ }^{\circ} 169$ da OIT e o Pacto de San José da Costa Rica concebeu um verdadeiro sistema de proteção dos direitos territoriais dos povos indígenas na Corte Interamericana orientado pelo princípio dubio pro homine, que impõe a aplicação da norma ou interpretação mais favorável quando se tratar de reconhecer direitos protegidos, mas também inversamente "la norma o a la interpretación más restringida cuando se trata de establecer restricciones permanentes al ejercicio de los derechos o su suspensión extraordinaria", como explica Monica PINTO (1997, p. 163).

De modo que, em casos de inevitável choque de direitos duplamente assegurados na CADH, como ocorreu no caso Yakye Axa vs. Paraguai, a Corte considerou útil e apropriado utilizar disposições da Convenção no 169 da OIT, levando em consideração a aplicação da norma mais ampla e clara sobre o tema.

A multiplicação de instrumentos internacionais de proteção dos direitos humanos e a complementariedade estabelecida entre eles acabou por estabelecer uma maior chance de efetividade da proteção dos direitos vindicados. "E não poderia ser de outra forma, em um domínio do direito em que predominam interesses comuns superiores, considerações de ordre public e a noção de garantia coletiva dos direitos protegidos", como destaca Antônio Augusto Cançado TRINDADE (2000, p. 105).

Seguindo a mesma diretriz, as normas internacionais voltadas à proteção da pessoa humana quando aplicadas no plano interno, pelo Poder Judiciário local, estabelecem um diálogo com a legislação nacional de modo a encontrar a justaposição mais adequada possível a implementar os direitos humanos tutelados, sob pena de se adstringir a uma interpretação dos tratados nacionalmente, "sem qualquer remissão ou lembrança da jurisprudência dos órgãos internacionais que os interpretam" (RAMOS, 2011, p. 521).

Revista Brasileira de Direito Internacional le-SSN: 2526-0219| Curitiba | v. 2 | n. 2 | p. 23 - 38 | Jul/Dez. 2016. 


\section{DIREITOS TERRITORIAIS INDÍGENAS NA ORDEM INTERNA}

O primeiro texto legal que fundamentou o direito dos índios no Brasil foi, ainda no período colonial, a Carta Régia de 1611 , seguida pelo Alvará de $1^{\circ}$ de abril de 1680 , que reconheceu o direito de posse permanente das terras tradicionalmente por eles ocupadas. Em 1775, outra norma também o reconheceu ao determinar que na concessão de sesmarias se respeitassem os direitos dos povos indígenas, primários e naturais senhores das terras por eles ocupadas.

Seguindo a visão integracionista, já durante a égide do Brasil Império, a Lei nº 601 , de 18/9/1850, inaugurou uma nova diretriz para a ocupação territorial brasileira, revogando a legislação portuguesa e garantindo alguns direitos aos índios. Contudo, a Constituição de 1891 foi silente sobre o tema.

O Decreto Legislativo $\mathrm{n}^{\mathrm{o}} 5.484$, de 27 de junho de 1928, tratou das liberdades e garantias individuais dos indígenas, contudo, trouxe em seu âmago defeitos congênitos acarretados pela visão assimilacionista. Por exemplo, classificava os índios conforme o grau de aculturação e institui o regime de tutela àquelas "não inteiramente adaptados."

A Constituição de 1934 foi a primeira a tratar dos direitos territoriais indígenas ao dispor em seu art. 129 que "Será respeitada a posse de terras de silvícolas que nelas se achem permanentemente localizados, sendo-lhes, no entanto, vedado aliená-las." Regra repetida na Constituição de 1946 (art. 216).

No mesmo rumo, a Constituição de 1967 também reconheceu o direito à posse nesses moldes, acrescentando, ainda, o direito ao usufruto exclusivo dos recursos naturais pelos "silvícolas.” O que se manteve com a Emenda Constitucional nº 1, de 17/10/1969.

Em 1973, a Lei n ${ }^{\circ}$ 6.001, conhecida como Estatuto do Índio, trouxe disposições mais minudentes sobre direitos dos povos indígenas, mas manteve a visão etnocêntrica, de modo que, como destaca Carlos Frederico Marés de SOUZA FILHO, “A relação do Estado com os índios no período militar oscilou entre a proteção paternalista e a tentativa de integração compulsória através de um processo que se chamou de emancipação (2012, p. 90).

A Constituição brasileira de 1988 inaugurou, como nenhuma outra antes, o imperativo de um Estado Democrático Multicultural e rompeu com o quadro normativo de índole integracionista.

Revista Brasileira de Direito Internacional le-SSN: 2526-0219| Curitiba | v. 2 | n. 2 | p. 23 - 38 | Jul/Dez. 2016. 
Ao garantir, no bojo do artigo 232, que os indígenas são partes legítimas para ingressar em juízo em defesa de seus direitos e interesses o texto constitucional conferiu-lhes a plena capacidade de direitos e deveres na ordem civil.

Operou-se, assim, o abandono do regime da tutela que se impunha como “instrumento da missão civilizadora, uma proteção concedida a essas 'grandes crianças' até que elas cresçam e venham a ser 'como nós'. Ou seja, respeita-se o índio como homem, mas exige-se que se despoje de sua condição étnica específica" (CUNHA, Manuela Carneiro da, 2012, p. 114).

A nova ordem constitucional elevou, ainda, os direitos indígenas às terras tradicionalmente ocupadas à categoria de direito originário conformando-o a um instituto heterodoxo de índole constitucional, e não "uma ortodoxa figura de Direito Civil" (ANJOS FILHO, 2011, p. 914).

A expressão tradicionalmente trazida no art. 231, caput, surgiu como solução intermediária ante ao impasse que se instalou durante a constituinte entre a proposta de fixação do direito às terras "ocupadas pelos índios" e às terras "de posse imemorial dos índios."

Seguindo tais diretrizes, o $\S 1^{\circ}$ do art. 231, tratou de modo não exaustivo, das terras tradicionalmente ocupadas pelo indígenas como sendo (i) as por eles habitadas em caráter permanente, (ii) as utilizadas para suas atividades produtivas, (iii) as imprescindíveis à preservação dos recursos ambientais necessários ao seu bem-estar e (iv) as necessárias a sua reprodução física e cultural, segundo seus usos, costumes e tradições.

Finalmente, o art. 67 do Ato das Disposições Constitucionais Transitórias da Constituição da República, estabeleceu um prazo de cinco anos para a conclusão das demarcações de terras indígenas, contados a partir da promulgação da Constituição, apesar desse prazo não ter sido estritamente cumprido pelo Estado brasileiro.

\section{O MARCO TEMPORAL DE 1988 E A COMPATIBILIDADE COM SISTEMA INTERAMERICANO DE DIREITOS HUMANOS}

O Supremo Tribunal Federal no emblemático julgamento da Pet $n^{\circ}$ 3.388/RR (Caso Raposa Serra do Sol), firmou o conceito denominado marco temporal de ocupação indígena

Revista Brasileira de Direito Internacional le-SSN: 2526-0219| Curitiba | v. 2 | n. 2 | p. 23 - 38 | Jul/Dez. 2016. 
no momento da promulgação da Constituição de 1988. A ementa do referido acórdão registrou sobre o ponto:

11.1. O marco temporal de ocupação. A Constituição Federal trabalhou com data certa — a data da promulgação dela própria (5 de outubro de 1988) como insubstituível referencial para o dado da ocupação de um determinado espaço geográfico por essa ou aquela etnia aborígene; ou seja, para o reconhecimento, aos índios, dos direitos originários sobre as terras que tradicionalmente ocupam.

Estabeleceu-se como limite à fixação de uma ocupação tradicional a análise quanto estado em que se encontrava a terra reivindicada (ocupada ou não pelos indígenas) no momento exato da promulgação da Constituição de 1988, estabelecendo-se como única exceção para o não atendimento desse requisito a efetiva comprovação de renitente esbulho.

Isso porque, seria necessário impedir a retrocessão até os idos tempos coloniais, de modo a afastar a chamada "Síndrome de Copacabana", visto que todo o território brasileiro foi, antes da chegada dos portugueses, habitado por povos nativos originários (ANJOS FILHO, 2011, p. 937).

Contudo, a interpretação dada pelo Supremo Tribunal Federal não está claramente expressada no texto constitucional. Em momento algum, seja no art. 231, 232 ou qualquer outro, há a referência à necessidade de ocupação tradicional no momento exato da promulgação da Constituição de 1988. E, ainda, que isso se aplicaria a todos os povos indígenas, uniformemente.

Ademais, a Constituição não exige a imemorialidade da ocupação, nem a ocupação no momento da promulgação da Constituição. Faz referência unicamente à "terras que tradicionalmente ocupem". Nesse passo, é importante distinguir ocupação tradicional de ocupação imemorial, uma vez que nem toda ocupação que remanesça nos dias de hoje, sem que se possa afirmar quando tenha iniciado é tradicional, bem como que nem toda ocupação tradicional será imemorial.

A tradicionalidade será demonstrada seguindo-se os indicativos da própria Constituição ( $§ 1^{\circ}$ do art. 231), tecnicamente formalizados pelo laudo antropológico - prova pericial, nos termos do Código de Processo Civil.

Questiona-se, ainda, o porquê da imposição do referido "marco temporal" com base na Constituição de 1988 e não se utilizando da Constituição de 1934 que já dispunha sobre o 
respeito da posse dos indígenas "permanentemente localizados" nas áreas questionadas. Como expõe José Afonso da SILVA (2015, p.10):

\begin{abstract}
Então, se há um marco temporal a ser firmado este é o da data da promulgação da Constituição de 1934, qual seja 16 de julho de 1934, que, por primeiro, deu consagração constitucional a esses direitos e garantia de sua proteção efetiva. A Constituição de 1988 é importante na continuidade desse reconhecimento constitucional, mas não é o marco, e deslocar esse marco para ela é fazer um corte na continuidade da proteção constitucional dos direitos indígenas, deixando ao desamparo milhares de índios e suas comunidades, o que, no fundo, é um desrespeito às próprias regras e princípios constitucionais que dão proteção aos direitos indígenas. (grifamos)
\end{abstract}

Mesmo que se alegue a necessidade de imposição do marco temporal para "por fim às disputas infindáveis sobre as terras, entre índios e fazendeiros," como afirmou o Ministro Gilmar Mendes em seu voto, tal entendimento colide com a própria norma constitucional que determina que o Estado deverá demarcar as terras indígenas, bem como que "são nulos e extintos, não produzindo efeitos jurídicos, os atos que tenham por objeto a ocupação, o domínio e a posse das terras a que se refere este artigo" (art. 231, $\S 6^{\circ}, \mathrm{CF}$ ).

Apesar da decisão proferida não ter efeitos vinculantes, mas tão somente ostentar força intelectual e persuasiva da mais alta corte do país, como esclareceu o Ministro Luís Roberto Barroso no julgamento dos embargos de declaração opostos, o marco temporal passou a ser replicado em diversos outros casos, tanto no Supremo Tribunal Federal, como em outros órgãos jurisdicionais (a título de exemplo cita-se: caso Limão Verde, pelo STF; caso Caso da Fazenda Passo Limpo em Laranjeiras do Sul/PR, pelo Tribunal Regional Federal da $4^{\text {a }}$ Região; caso da terra indígena Mato Preto em Erechim/RS, pelo juízo federal de $1^{\circ}$ grau).

Contudo, numa ordem jurídica plural, o sistema interno de proteção dos direitos fundamentais deve dialogar com o sistema internacional de proteção dos direitos humanos, até porque bem antes da produção do controle hegemônico do Direito por parte do Estado nacional soberano, subsistiu uma rica e longa trajetória histórica de práticas autônomas de elaboração legal e comunitária, de modo que o pluralismo jurídico orienta a uma visão antidogmática e interdisciplinar que advoga a supremacia de fundamentos ético-sociológicos sobre critérios tecnoformais (WOLKMER, 2001, p. 183).

O Convenção no 169 da OIT, da qual o Brasil, frise-se, é signatário, impõe o dever do Estado de "adotar as medidas que sejam necessárias para determinar as terras que os povos interessados ocupam tradicionalmente e garantir a proteção efetiva dos seus direitos de

Revista Brasileira de Direito Internacional le-SSN: 2526-0219| Curitiba | v. 2 | n. 2 | p. 23 - 38 | Jul/Dez. 2016. 
propriedade e posse" (art. 14, 2). Fixa, ademais, de modo bastante claro e amplo, o direito dos povos indígenas à posse das terras que tradicionalmente ocupam.

Suprime-se aqui, propositalmente, a expressão "propriedade", constante no artigo 14.1 da referida Convenção porque sua leitura deve ser feita em conjunto com o artigo 34, que estabelece o princípio da flexibilidade na aplicação da Convenção, "levando-se em conta as condições peculiares de casa país.”

Isso porque no Brasil, como dispõe o artigo 20, inciso XI da Constituição Federal brasileira, as terras indígenas são bens da União. Portanto, é preciso assentar que as comunidades indígenas brasileiras possuem direito à posse, mas não à propriedade das terras que ocupem e isso em nada colide com a Convenção nº 169 da OIT, já que ela própria permite tal aplicação.

Situação diferente ocorre quando se impõe aos povos indígenas a obrigação de ocupação tradicional no momento exato da promulgação da Constituição de 1988 para que seja-lhes reconhecido o direito à posse das terras que ocupam. Tal entendimento não encontra guarida na própria Constituição, que nada fala sobre tal requisito, muito menos nas normas de proteção dos direitos humanos internacionais, especialmente o Pacto de San José e a Convenção $\mathrm{n}^{\circ} 169$.

A mercê de uma inferência supralegal ou da formação de um bloco de constitucionalidade formado pela Constituição Federal e os tratados internacionais de direitos humanos, não emerge contradição entre a norma interna e a norma internacional que justifique a aplicação pelo Supremo Tribunal Federal do referido "marco temporal." Pelo contrário. Ambas as normas são mais protetivas do que a interpretação dada pela corte brasileira, que além de reduzir a amplitude dos direitos territoriais indígenas, impôs a todo Poder Judiciário nacional uma diretriz que vulnera o próprio direito fundamental protegido.

É de se lembrar que a responsabilidade dos Estados por violação aos direitos humanos se impõe não somente em razão dos atos de particulares mas também, e talvez principalmente (já que os Estados são os maiores violadores de direitos humanos), em razão de atos tanto dos Poderes Legislativo, Executivo e Judiciário (RAMOS, 2004, p. 168).

Dessa forma, a responsabilização internacional do Estado por violação de direitos humanos originada por ato judicial surge não somente quanto a decisão é tardia ou inexistente, mas também quando ela é, em seu mérito, violadora de direitos humanos. Nessa linha, argumenta Daniel SARMENTO (2013, p.14):

Revista Brasileira de Direito Internacional le-SSN: 2526-0219| Curitiba | v. 2 | n. 2 | p. 23 - 38 | Jul/Dez. 2016. 
Ao interpretar a Constituição, o STF deve considerar este compromisso internacional voltado ao respeito do direito humano à terra tradicionalmente ocupada pelos povos indígenas, buscando a exegese que melhor proteja e promova tal direito no âmbito interno. Não fazê-lo, poderá inclusive expor o país à responsabilização no plano internacional, pela violação de direitos humanos que se comprometeu a garantir. E a melhor interpretação da Constituição, sem sombra de dúvida, é a que qualifica o direito do art. 231 da Constituição como cláusula pétrea, de modo a protegê-lo mais robustamente diante das maiorias legislativas.

Portanto, o Poder Judiciário não é independente do Estado e pode, mediante uma sentença que seja incompatível com uma regra de Direito Internacional comprometer a responsabilidade internacional do Estado (ARÉCHAGA, 1980, p. 131).

Para a Corte Interamericana de Direitos Humanos é perfeitamente possível responsabilizar um Estado-parte em razão de ato atentatório aos direitos humanos decorrente de ato judicial. No caso "La Última Tentación de Cristo" (Olmedo Bustos y otros) vs. Chile se fixou que:

Segundo, cualquier acto u omisión del Estado, por parte de cualquier de los Poderes - Ejecutivo, Legislativo o Judicial - o agentes del Estado, independientemente de su jerarquía, en violación de un tratado de derechos humanos, genera la responsabilidad internacional del Estado Parte en cuestión; Tercero, la distribución de competencias entre los poderes y órganos estatales, y el principio de la separación de poderes, aunque sean de la mayor relevancia en el ámbito del derecho constitucional, no condicionan la determinación de la responsabilidad internacional de un Estado Parte en un tratado de derechos humanos.

Tal posicionamento foi reafirmado pela CIDH ao julgar o caso Barrios Alto vs. Peru de modo que:

Hay toda una jurisprudencia internacional secular que se orienta claramente en el sentido de que "el origen de la responsabilidad internacional del Estado puede residir en cualquier acto u omisión de cualesquiera de los poderes o agentes del Estado (sea del Ejecutivo, o del Legislativo, o del Judicial).

Outro não é o entendimento da Corte Européia de Direitos Humanos que, nos célebres casos Marckx (1979) e Vermeire (1987), determinou a alteração de vários dispositivos do Código Civil belga (que tratavam sobre filiação ilegítima), por violarem a Convenção 
Européia, apesar de a Corte de Cassação belga haver declarado que não existia afronta à Convenção.

Pelo exposto, mostra-se factível a responsabilização do Estado brasileiro por ato do Poder Judiciário que amesquinhe o acesso dos povos indígenas ao direito às terras que ocupam, em razão da imposição de requisito não expresso tanto na Convenção $n^{\circ} 169$ da OIT, como na própria Constituição Federal de 1988, qual seja, a ocupação dessas terras no momento da promulgação da Constituição de 1988 (o chamado "marco temporal").

\section{Conclusão}

O rompimento da visão etnocêntrica, discriminatória e excludente em sede de direitos territoriais indígenas impõe aos Estados mudanças verdadeiramente estruturais. Parece não mais caber uma leitura das normas protetivas de Direitos Humanos de modo desconectado com seus propósitos, encarando-as como simples protocolos de intenção.

As normas integrativas de acesso dos índios às terras que ocupem são corolários do próprio direito ao reconhecimento e expressão da sua dignidade. Ademais, quando diversas normas (nacionais e internacionais) tratam de direitos humanos não será o princípio da especialidade ou o cronológico que indicará qual a norma deverá ser aplicada pelo Estadoparte, mas sim o princípio do in dubio pro homine, para que se garanta a maior proteção possível ao direito que se visa assegurar.

O Supremo Tribunal Federal do Brasil, ao julgar a Pet 3.388/RR (Caso Raposa Serra do Sol), formulou um requisito não escrito em nenhuma norma que trate sobre os direitos dos povos indígenas às suas terras, qual seja, a necessidade de ocupação de fato da área no momento da promulgação da Constituição de 1988 , o chamado "marco temporal."

Tal requisito, além de não constar textualmente nas normas sobre o assunto, diminui o espectro da proteção dos direitos territoriais indígenas e exclui um grande número de comunidades do processo demarcatório.

Por tal razão, o Brasil, por ser signatário da Convenção Interamericana de Direitos Humanos e por se submeter à jurisdição internacional da Corte Interamericana, pode ser responsabilizado, uma vez que a Corte já firmou entendimento que os atos do Poder Judiciário dos Estados-parte não são insindicáveis em sede internacional.

Revista Brasileira de Direito Internacional le-SSN: 2526-0219| Curitiba | v. 2 | n. 2 | p. 23 - 38 | Jul/Dez. 2016. 


\section{REFERÊNCIAS}

ANJOS FILHO, Robério Nunes dos. O Supremo Tribunal Federal e os Direitos dos Povos Indígenas. In: SARMENTO, Daniel; SARLET, Ingo (coord.). Direitos Fundamentais no Supremo Tribunal Federal: Balanço e Crítica. Rio de Janeiro: Lumen Juris, 2011, p. 911954.

ARÉCHAGA, Eduardo Jiménez de. El Derecho Internacional Contemporaneo, Madri: Tecnos, 1980.

BARRETO, Helder Girão. Direitos Indígenas: Vetores Constitucionais. Curitiba: Juruá, 2004.

COMPARATO, Fábio Konder. A afirmação histórica dos direitos humanos. $7^{a}$ ed. São Paulo: Saraiva, 2010.

CUNHA, Manuela Carneiro da. Índios no Brasil: história, direitos e cidadania. São Paulo: Claro Enigma, 2012.

LIPPEL, Alexandre Gonçalves. O conceito de terras indígenas na Constituição Federal de 1988: Crítica à decisão do Supremo Tribunal Federal no caso Raposa Serra do Sol. Curitiba: Editora CRV, 2014.

MELO, Mario. Recent advances in the justiciability of indigenous rights in the inter-american system of human rights. Sur - International Journal on Human Rights. N. 4, vol.3. Disponível em <http://www.conectas.org/Arquivos/edicao/publicacoes/publicacao2014131141932113-31802017.pdf>. Acesso em 02 de junho de 2016.

PINTO, Monica. El principio pro homine: criterios de hermenêutica y pautas para La regulación de lós derechos humanos. In: La aplicación de lós tratados de derechos humanos por lós tribunales locales. Buenos Aires: Ediar, Centro de Estudios Legales y Sociales-Editorial del Puerto, 1997.

PIOVESAN, Flávia. Igualdade, Diferença e Direitos Humanos: Perspectivas Global e Regional. In: SARMENTO, Daniel; IKAWA, Daniela e PIOVESAN, Flávia. Igualdade, Diferença e Direitos Humanos. Rio de Janeiro: Lumen Juris, 2010.

RAMOS, André de Carvalho. Pluralidade das ordens jurídicas: uma nova perspectiva na relação entre o Direito Internacional e o Direito Constitucional. Revista da Faculdade de Direito da Universidade de São Paulo, v. 106/107, jan./dez. 2011.

RAMOS, André de Carvalho. Responsabilidade Internacional por Violação dos Direitos Humanos. Rio de Janeiro: Renovar, 2004.

SANTOS, Boaventura de Sousa. Uma concepção multicultural de Direitos Humanos. Lua Nova Revista de Cultura e Política. Governo e Direitos - CEDEC, n 39, 1997. 
SARMENTO, Daniel. Nota técnica: A PEC 215/00 e as Cláusulas Pétreas. Disponível em $<$ http://www.dsarmento.adv.br/content/3-publicacoes/23-a-pec-215-00-e-as-clausulaspetreas/daniel-sarmento-a-pec-215-00-e-as-clausulas-petreas.pdf $>$. Acesso em 29 de maio de 2016.

SEN, Amartya. Identidade e violência: a ilusão do destino. Lisboa: Edições Tinta-da-China, 2007.

SILVA, José Afonso da. Parecer sobre marco temporal da Constituição de 1988. Disponível em <https://mobilizacaonacionalindigena.files.wordpress.com/2016/05/parecerjosc3a9-afonso-marco-temporal_.pdf>, Acesso em 05 de junho de 2016.

SOUZA FILHO, Carlos Frederico Marés de. O renascer dos povos indígenas para o direito. Curitiba: Juruá, 2008.

TAYLOR, Charles. A Política de Reconhecimento. In: TAYLOR, Charles (org.). Multiculturalismo. Lisboa: Instituto Piaget, 1994.

TODOROV, Tzvetan. A conquista da América. $4^{\text {a }}$ ed. São Paulo: WMF Martins Fontes, 2010.

TRINDADE, Antônio Augusto Cançado. O Sistema Interamericano no limiar do novo século. In: GOMES, Luiz Flávio; PIOVESAN, Flávia. O sistema interamericano de proteção dos direitos humanos e o direito brasileiro. São Paulo: Revista dos Tribunais, 2000.

WOLKMER, Antônio Carlos. Pluralismo Jurídico: Fundamentos de uma nova cultura do Direito. $3^{a}$ ed. São Paulo: Alfa-Ômega, 2001. 